\title{
Late Onset Agranulocytosis with Clozapine Associated with HLADR4 Responding to Treatment with Granulocyte Colony-stimulating Factor: A Case Report and Review of Literature
}

\author{
Aakanksha Singh', Sandeep Grover ${ }^{1}$, Pankaj Malhotra ${ }^{2}$, Subhash C. Varma ${ }^{2}$ \\ Departments of ${ }^{1}$ Psychiatry and ${ }^{2}$ Internal Medicine, Post Graduate Institute of Medical Education and Research, Chandigarh, India
}

\begin{abstract}
Agranulocytosis as a side effect of clozapine has been reported to be associated with initial phases of treatment, i.e., first six months. Agranulocytosis with clozapine during the initial phases of treatment has been linked to genetic vulnerability in the form of variations in the human leukocyte-antigen haplotypes. However, there is limited literature on late onset agranulocytosis with clozapine and this has very rarely been linked to human leukocyte-antigen haplotypes vulnerability. In this report we review the existing data on late onset agranulocytosis with clozapine and describe the case of a young man, who developed agranulocytosis with clozapine after 35 months of treatment and was found to have genetic vulnerability in form of being positive for HLA DR4. This case highlights underlying autoimmune immune mechanism in clozapine-induced agranulocytosis and the need for frequent blood count monitoring on clozapine even after the initial 6 months of starting treatment especially in patients with genetic vulnerability to develop this condition.
\end{abstract}

KEY WORDS: Clozapine; Agranulocytosis; Neutropenia.

\section{INTRODUCTION}

Since the beginning of its use, the heamatological side effects of clozapine in the form of agranulocytosis and neutropenia have been an important issue with the patients and clinicians. ${ }^{1,2)}$ Available data suggests that overall the incidence rate of agranulocytosis is $0.38 \%$ among patients receiving clozapine. ${ }^{1)}$ Most of the evidence suggests that whenever neutropenia occurs with clozapine, it usually occurs during the early phase of treatment, i.e., highest in first 6 weeks to 18 months after the onset of treatment. ${ }^{1,3)}$ Due to this, more intense monitoring is suggested during the initial phase of the treatment, i.e., first 18 weeks. ${ }^{3)}$ However, there are few reports of late onset neutropenia with clozapine after as long as 19 years of use of clozapine. ${ }^{4-17)}$ Studies have attempted to find out the factors associated with clozapine induced neutropenia. Among the various factors reported to be associated with clozapine induced neutropenia, there is some data to suggest that genetic vulner-

\footnotetext{
Received: June 8, 2015 / Revised: August 12, 2015

Accepted: September 1, 2015

Address for correspondence: Sandeep Grover, MD

Department of Psychiatry, Postgraduate Institute of Medical

Education and Research, Chandigarh 160012, India

Tel: +91-172-2756807, Fax: +91-172-2756807

E-mail: drsandeepg2002@yahoo.com
}

ability in the form of variations in the human leukocyteantigen haplotypes predisposes a person to develop neutropenia. ${ }^{18)}$

In this report, we present a case of late onset neutropenia with clozapine who on investigation was found positive for human leukocyte antigen (HLA) DR4.

\section{CASE}

A male patient, University Graduate, smoker, suffering from treatment resistant schizophrenia was started on clozapine at the age of 32 years. Initially he tolerated the dose of clozapine well and showed partial response to clozapine $450 \mathrm{mg} /$ day. Later in view of partial response, trifluoperazine was added and he was stabilized on clozapine $450 \mathrm{mg} /$ day and trifluoperazine $20 \mathrm{mg} /$ day after 9 months of initiation of clozapine. Regular weekly hematological monitoring was done during initial 5 months, followed by monitoring at monthly intervals. He maintained well with this combination for next 26 months. However after this on one occasion he all of a sudden developed high grade fever, which was not associated with any specific systemic signs and symptoms. A haemogram was ordered and it revealed a total leucocyte count of $1,100 / \mathrm{mm}^{3}$

(a) This is an Open-Access article distributed under the terms of the Creative Commons Attribution Non-Commercial License (http://creativecommons.org/licenses/by-nc/4.0) which permits unrestricted non-commercial use, distribution, and reproduction in any medium, provided the original work is properly cited. 
with neutrophils count of zero. The differential count showed $98 \%$ lymphocytes, $1 \%$ monocytes and $1 \%$ eosinophils, along with hemoglobin level of $13.5 \mathrm{~g} / \mathrm{dL}$ and platelet count of $1.5 / \mu 1$. There was no history of administration of any antibiotics, chemotherapeutic agent, radiotherapy, anti-epileptic medications.

He was immediately hospitalized, all psychotropics were stopped. Physical examination revealed a small ulcer on the prepuce and a tender swelling in his right axilla. He was investigated for possible causes of leucopenia and neutropenia in the form of heamatological malignancies, systemic lupus erythematous, Crohn's disease, rheumatoid arthritis, infections (bacterial, tubercular and viral in the form of human immunodeficiency virus, Epstein-Barr virus (EBV), cytomegalus virus, hepatitis). Investigations in form of serum electrolytes, renal function test, liver function tests, chest X-ray, urine examination (routine and culture sensitivity), blood culture for bacteria and fungus, electrocardiogram and echocardiography did not reveal any abnormality. Serum calcium was $8.24 \mathrm{mg} / \mathrm{dl}$, hepatitis $\mathrm{B}$ antigen and hepatitis $\mathrm{C}$ antibody were negative. EBV immunoglobulin M antibody (IgM Ab), Widal test, dengue serology (IgM Ab), smear for malaria parasite and ultrasound abdomen did not reveal any abnormality. Venereal Disease Research Laboratory test was found to be negative. The fine needle aspiration cytology of the mass in the axilla was positive for Proteus mirabilis which was sensitive to piperacillin and tazobactum. Fever improved after antibiotic treatment was started.

In view of no other detectable cause, the leucopenia and neutropenia were attributed clozapine and the infection was considered to be secondary to the neutropenia. He was further investigated and was found positive for HLA DR4 (DRB1*04) and HLA DQB1*02:01, 1*02:02, $1 * 03: 02$. He was managed with granulocyte colony-stimulating factor (G-CSF) at the dose of $5 \mu \mathrm{g} / \mathrm{kg} /$ day for 7 days, along with broad-spectrum antibiotics. Over the period of one week his leucocyte and neutrophil count normalized. In view of the genetic vulnerability clozapine re-challenge was not done and he was managed with a combination of antipsychotics (trifluoperazine and olanzapine) over next one year, with which he showed partial response in terms of improvement in psychotic symptoms.

\section{DISCUSSION}

We searched the PubMed search engine and available data suggests that there is limited literature in the form of case reports of late onset neutropenia and late onset agra- nulocytosis associated with clozapine, ${ }^{4-17)}$ with one of the reports showing the association after 19 years of use of clozapine. ${ }^{5)}$ In a review of literature, authors reported 16 case reports available prior to 2012 . $^{4,8-11,13,16,19-25)}$ The authors themselves reported the 17th case. In our literature search of PubMed, we came across 3 more cases. ${ }^{10,17,26)}$ The data of all the cases is presented in Table 1. In majority of the case reports, patients were receiving concomitant medications along with clozapine, with valproate ( 5 cases), risperidone ( 7 cases) and haloperidol (3 cases) being the commonly used concomitant medications. ${ }^{4,6,10,13,15-17)}$ In other cases concomitant medication use involved use of antidepressants, anti-tubercular drugs, etc. ${ }^{7,8,12,15)}$ In 6 cases, late onset agranulocytosis/neutropenia was seen with clozapine monotherapy. In most of these cases, the patients were not rechallenged with clozapine. ${ }^{4,5,7,9,15,17)}$ Our case developed agranulocytosis while on clozapine for 35 months. In terms of concomitant medication our patient was receiving trifluoperazine, for about 1.5 years prior to development of agranulocytosis. Accordingly it can be concluded that trifluoperazine would not have contributed to agranulocytosis. Our case adds to the limited literature of late onset agranulocytosis/neutropenia and suggests that regular haematological monitoring should be done in patients receiving clozapine. In our case neutropenia improved rapidly over the period of 1 week. The rapid resolution of neutropenia after stoppage of clozapine possibly suggests that the neutropenia was due immune mediated destruction of neutrophils, which resolved with stoppage of offending agent. The Naranjo probability score for our case was 7 , indicative of probable association. ${ }^{27}$

Over the years few researchers have attempted to find the risk factors associated with development of clozapine-induced agranulocytosis. The factors identified to have some association with clozapine-induced agranulocytosis include HLA class III genes for tumor necrosis factor (TNF) and heat shock proteins (HSP), increased expression of proapoptotic genes bax $\alpha, \mathrm{p} 53$, and bik and presence of certain HLA phenotypes. With regard to the HLA class III genes for TNF and HSP it is proposed that the formation of oxidized clozapine intermediates may decrease the survival of granulocytes in individuals who carry clozapine-induced agranulocytosis susceptibilityassociated HSP or TNF variants. ${ }^{28)}$ Increased expression of proapoptotic genes bax $\alpha, \mathrm{p} 53$, and bik has been linked to oxidative mitochondrial stress in neutrophils of clozapine-treated patients and suggest that free radicals and oxidative stress possibly up-regulate proapoptotic genes and contribute to the induction of apoptosis and clozapine-in- 


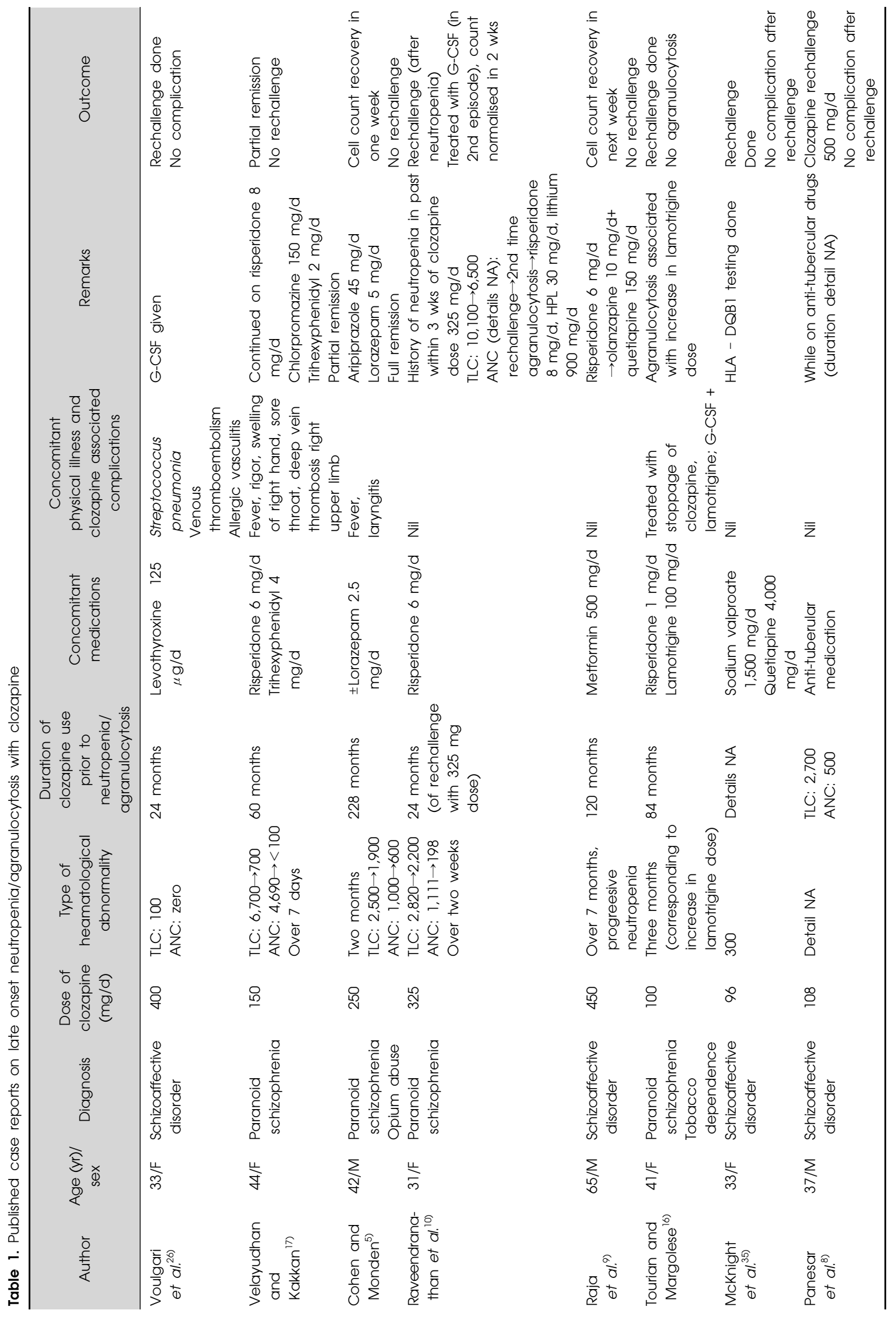




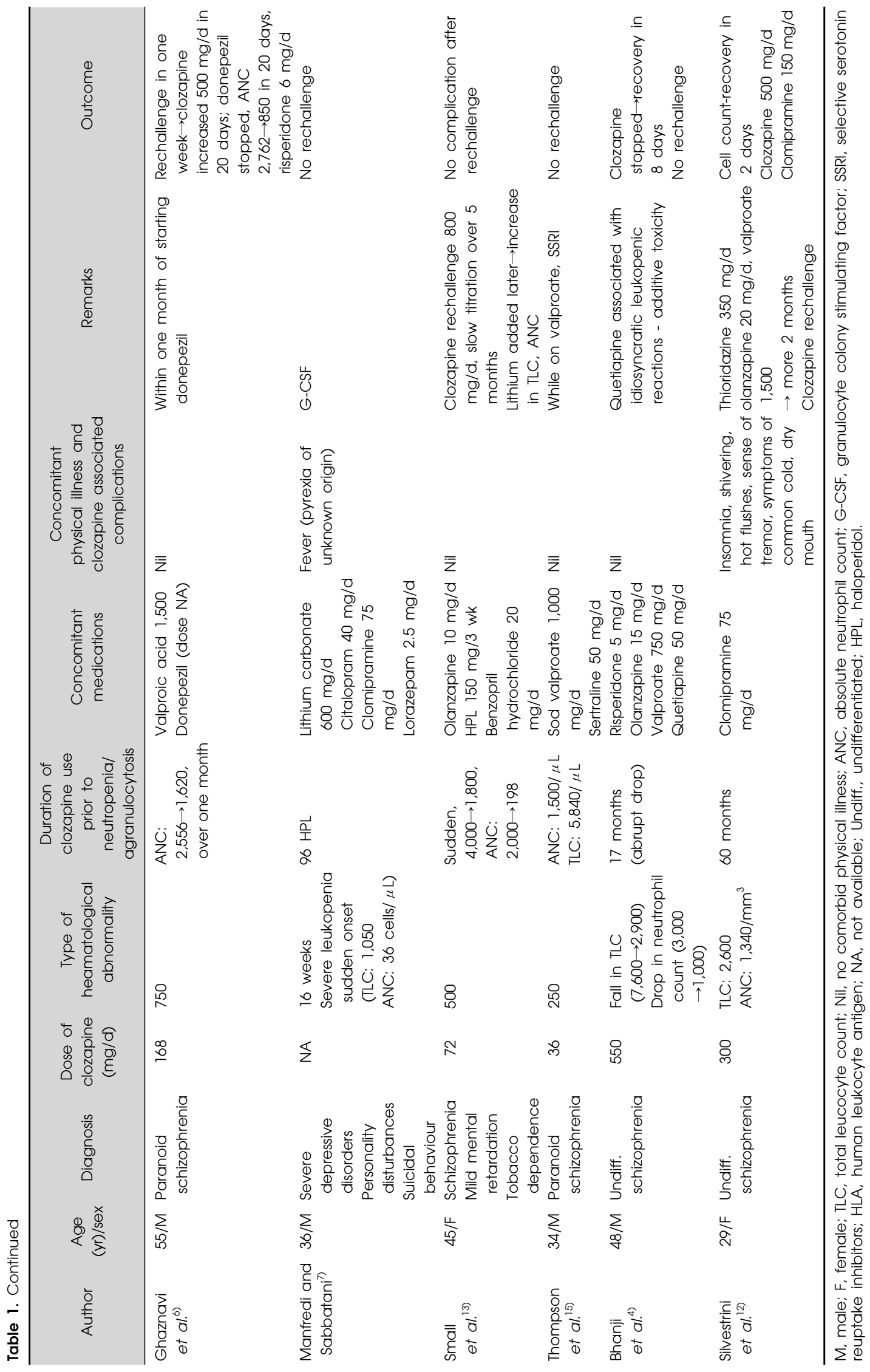


duced agranulocytosis. ${ }^{29)}$ There is lack of consensus for type of HLA phenotype associated with clozapine-induced agranulocytosis. Lieberman et al. ${ }^{30)}$ reported that Ashkenazi Jews exhibiting the phenotype HLA B38, DR4, DQW3 are at an increased risk of agranulocytosis, as are non-Jewish individuals with HLA phenotype B7, DR2, DQ2. They also suggested that specific gene products encoded in the major histocompatibility complex may be involved in mediating drug toxicity. Yunis et al., ${ }^{31)}$ in an extension of the findings of Lieberman et al., ${ }^{30)} \mathrm{ob}-$ served that in Ashkenazi patients the susceptibility class II haplotype is DRB $1 * 0402$, DQB $1 * 0302$, and in non-Jewish patients, DRB1*02, DQB1*0502 and DQA1*0102 were associated with vulnerability to develop clozapine-induced agranulocytosis. However, in another study involving 103 patients with a history of clozapine induced agranulocytosis no significant association was noted between HLA-A, -B, -C, -DR, -DQ, number of neutrophil-specific alloantigens and susceptibility to clozapine-induced agranulocytosis. ${ }^{32)}$ However, these results were later questioned when emphasis was placed on statistical methodology used for statistical analysis of simultaneous occurrence of multiple HLAs, in an attempt to predict vulnerability to clozapine-induced agranulocytosis. ${ }^{33)}$ Another study on Israeli Jewish patients showed that HLA B38 conferred susceptibility for clozapine-induced agranulocytosis. ${ }^{33)}$ Further on combining the data of Lieberman et $a l .^{30)}$ and Yunis et $a l .{ }^{31)}$, the authors proposed that the gene susceptible for clozapine induced agranulocytosis was located in the HLA-B locus rather than in the DR/DQ region. ${ }^{34)}$ Recent report has associated increased risk of developing clozapine-induced agranulocytosis in patients with DQB1 genotype. ${ }^{35)}$ Our case was found positive for HLA DR4 (DRB1*04) and HLA DQB1*02:01, $1 * 02: 02$, $1 * 03: 02$, suggesting that late onset neurotropenia also may be related to HLA gene susceptibility. In a recent largest study which included, 163 cases authors found association between clozapine induced agranulocytosis and HLA-DQB1 and HLA-B especially two amino acids sequences, i.e., HLA-DQB1 $126 \mathrm{Q}$ and HLA-B 158T. However, the authors concluded that they could not distinguish as to whether these amino acids had causal role or just conferred risk. ${ }^{36)}$

Besides the genetic vulnerability other factors which have been considered as risk factors for bone marrow suppression with clozapine include increased age (i.e., more than 40 years), female gender, African race, and concomitant medications, ${ }^{3,37,38)}$ eosinophilia antedating the onset of neutropenia. ${ }^{39)}$
The hematopoietic growth factors, G-CSF and granulocyte macrophage colony stimulating factor increase the proliferation and differentiation of myeloid precursor cells. The recombinant human granulocyte growth factor G-CSF (filgrastim) is approved for the correction of severe clozapine-related neutropenia. ${ }^{40-42)}$ In our patient, immediate discontinuation of clozapine upon diagnosis, prompt initiation of antibiotic therapy, and G-CSF titration managed the early increase in the neutrophil count and the improvement of the patient's clinical presentation.

\section{REFERENCES}

1. Alvir JM, Lieberman JA, Safferman AZ, Schwimmer JL, Schaaf JA. Clozapine-induced agranulocytosis. Incidence and risk factors in the United States. $N$ Engl J Med 1993;329:162-167.

2. Hummer M, Kurz M, Barnas C, Saria A, Fleischhacker WW. Clozapine-induced transient white blood count disorders. J Clin Psychiatry 1994;55:429-432.

3. Atkin K, Kendall F, Gould D, Freeman H, Liberman J, O'Sullivan D. Neutropenia and agranulocytosis in patients receiving clozapine in the $U K$ and Ireland. Br J Psychiatry 1996;169:483-488.

4. Bhanji NH, Margolese HC, Chouinard G, Turnier L. Lateonset agranulocytosis in a patient with schizophrenia after 17 months of clozapine treatment. J Clin Psychopharmacol 2003;23:522-523.

5. Cohen D, Monden M. White blood cell monitoring during long-term clozapine treatment. Am J Psychiatry 2013;170: 366-369.

6. Ghaznavi S, Nakic M, Rao P, Hu J, Brewer JA, Hannestad $\mathrm{J}$, et al. Rechallenging with clozapine following neutropenia: treatment options for refractory schizophrenia. Am J Psychiatry 2008;165:813-818.

7. Manfredi R, Sabbatani S. Clozapine-related agranulocytosis associated with fever of unknown origin, protective hospitalisation, and multiple adverse events related to the administration of empiric antimicrobial treatment. Pharmacoepidemiol Drug Saf 2007;16:1285-1289.

8. Panesar N, Pai N, Valachova I. Late onset neutropenia with clozapine. Aust N Z J Psychiatry 2011;45:684.

9. Raja M, Azzoni A, Maisto G. Late onset neutropenia associated with clozapine. J Clin Psychopharmacol 2011; 31:780-781.

10. Raveendranathan D, Sharma E, Venkatasubramanian G, Rao MG, Varambally S, Gangadhar BN. Late-onset clozapineinduced agranulocytosis in a patient with comorbid multiple sclerosis. Gen Hosp Psychiatry 2013;35:574.e5-6.

11. Sedky K, Shaughnessy R, Hughes T, Lippmann S. Clozapineinduced agranulocytosis after 11 years of treatment. Am J Psychiatry 2005;162:814.

12. Silvestrini C, Arcangeli T, Biondi M, Pancheri P. A second trial of clozapine in a case of granulocytopenia. Hum Psychopharmacol 2000;15:275-279.

13. Small JG, Weber MC, Klapper MH, Kellams JJ. Rechallenge of late-onset neutropenia with clozapine. J Clin Psychopharmacol 2005;25:185-186.

14. Tamam L, Kulan E, Ozpoyraz N. Late onset neutropenia during clozapine treatment. Psychiatry Clin Neurosci 2001; 55:547-548. 
15. Thompson A, Girishchandra B, Castle D, Orr K. Late onset neutropenia with clozapine. Can J Psychiatry 2004;49:647648.

16. Tourian L, Margolese HC. Late-onset agranulocytosis in a patient treated with clozapine and lamotrigine. J Clin Psychopharmacol 2011;31:665-667.

17. Velayudhan R, Kakkan S. Late onset clozapine induced agranulocytosis. Indian J Psychol Med 2014;36:425-427.

18. Corzo D, Yunis JJ, Yunis EJ, Howard A, Lieberman JA. HSP70-2 $9.0 \mathrm{~kb}$ variant is in linkage disequilibrium with the $H L A-B$ and DRB1* alleles associated with clozapineinduced agranulocytosis. J Clin Psychiatry 1994;55 Suppl B:149-152.

19. Godleski LS, Sernyak MJ. Agranulocytosis after addition of risperidone to clozapine treatment. Am J Psychiatry 1996; 153:735-736.

20. Kutscher EC, Robbins GP, Kennedy WK, Zebb K, Stanley M, Carnahan RM. Clozapine-induced leukopenia successfully treated with lithium. Am J Health Syst Pharm 2007;64: 2027-2031.

21. Nongpiur A, Praharaj SK, Sarkar S, Das B. Delayed onset of clozapine-induced leucopenia. Am $J$ Ther 2012;19: el18-e119.

22. Sénéchal A, Landry P, Deschamps R, Lessard M. [Neutropenia in a patient treated with clozapine in combination with other psychotropic drugs]. Encephale 2002;28:567-569. Dutch.

23. Patel NC, Dorson PG, Bettinger TL. Sudden late onset of clozapine-induced agranulocytosis. Ann Pharmacother 2002; 36:1012-1015.

24. Peacock L, Gerlach J. Clozapine treatment in Denmark: concomitant psychotropic medication and hematologic monitoring in a system with liberal usage practices. $J$ Clin Psychiatry 1994;55:44-49.

25. Latif Z, Malik MA, Jabbar F, Ahmed Y, McDonough C. Clozapine-induced late leukopenia. Ir J Med Sci 2012;181: 139-141.

26. Voulgari C, Giannas R, Paterakis G, Kanellou A, Anagnostopoulos N, Pagoni S. Clozapine-induced late agranulocytosis and severe neutropenia complicated with Streptococcus pneumonia, venous thromboembolism, and allergic vasculitis in treatment-resistant female psychosis. Case Rep Med 2015;2015:703218

27. Naranjo CA, Busto U, Sellers EM, Sandor P, Ruiz I, Roberts EA, et al. A method for estimating the probability of adverse drug reactions. Clin Pharmacol Ther 1981;30:239-245.

28. Husain Z, Almeciga I, Delgado JC, Clavijo OP, Castro JE, Belalcazar V, et al. Increased FasL expression correlates with apoptotic changes in granulocytes cultured with oxidized clozapine. Toxicol Appl Pharmacol 2006;214:326-334.
29. Fehsel K, Loeffler S, Krieger K, Henning U, Agelink M, Kolb-Bachofen V, et al. Clozapine induces oxidative stress and proapoptotic gene expression in neutrophils of schizophrenic patients. J Clin Psychopharmacol 2005;25:419-426.

30. Lieberman JA, Yunis J, Egea E, Canoso RT, Kane JM, Yunis EJ. HLA-B38, DR4, DQw3 and clozapine-induced agranulocytosis in Jewish patients with schizophrenia. Arch Gen Psychiatry 1990;47:945-948.

31. Yunis JJ, Corzo D, Salazar M, Lieberman JA, Howard A, Yunis EJ. HLA associations in clozapine-induced agranulocytosis. Blood 1995;86:1177-1183.

32. Claas FH, Abbott PA, Witvliet MD, D'Amaro J, Barnes PM, Krupp P. No direct clinical relevance of the human leucocyte antigen (HLA) system in clozapine-induced agranulocytosis. Drug Saf 1992; 7 Suppl 1:3-6.

33. Abt K, Gülich A, Krupp P, Reinberg W. HLA-associations in Leponex/Clozaril (clozapine)-induced granulocytopenia and agranulocytosis. Statistical viewpoints. Drug Saf 1992;7 Suppl 1:10-16.

34. Valevski A, Klein T, Gazit E, Meged S, Stein D, Elizur A, et al. HLA-B38 and clozapine-induced agranulocytosis in Israeli Jewish schizophrenic patients. Eur J Immunogenet 1998;25:11-13.

35. McKnight $\mathrm{C}$, Guirgis $\mathrm{H}$, Votolato N. Clozapine rechallenge after excluding the high-risk clozapine-induced agranulocytosis genotype of HLA-DQB1 $6672 G>C$. Am J Psychiatry 2011;168:1120.

36. Goldstein JI, Jarskog LF, Hilliard C, Alfirevic A, Duncan $\mathrm{L}$, Fourches $\mathrm{D}$, et al. Clozapine-induced agranulocytosis is associated with rare HLA-DQB1 and HLA-B alleles. Nat Commun 2014;5:4757.

37. Baldessarini RJ, Frankenburg FR. Clozapine. A novel antipsychotic agent. $N$ Engl J Med 1991;324:746-754.

38. Lekhakula A, Swasdikul D. Drug-induced agranulocytosis: experience in two university hospitals. J Med Assoc Thai 1991;74:121-130.

39. Hummer M, Sperner-Unterweger B, Kemmler G, Falk M, Kurz M, Oberbauer $\mathrm{H}$, et al. Does eosinophilia predict clozapine induced neutropenia? Psychopharmacology (Berl) 1996;124:201-204.

40. Nielsen H. Recombinant human granulocyte colony-stimulating factor (rhG-CSF; filgrastim) treatment of clozapine-induced agranulocytosis. J Intern Med 1993;234:529-531.

41. Sedky K, Lippmann S. Psychotropic medications and leukopenia. Curr Drug Targets 2006;7:1191-1194.

42. Whiskey E, Taylor D. Restarting clozapine after neutropenia: evaluating the possibilities and practicalities. CNS Drugs 2007;21:25-35. 